\title{
Correlation of Muscle Invasion in Bladder Cancer with Cell Adhesion Properties and Oncoprotein Overexpression Using E-Cadherin and HER2/neu Immunohistochemical Markers
}

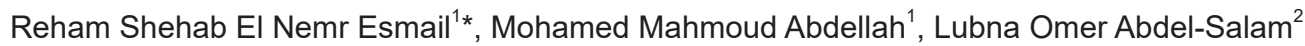 \\ ${ }^{1}$ Department of Pathology, Faculty of Medicine, Fayoum University, Faiyum, Egypt; ${ }^{2}$ Department of Pathology, Faculty of \\ Medicine, Cairo University, Giza, Egypt
}

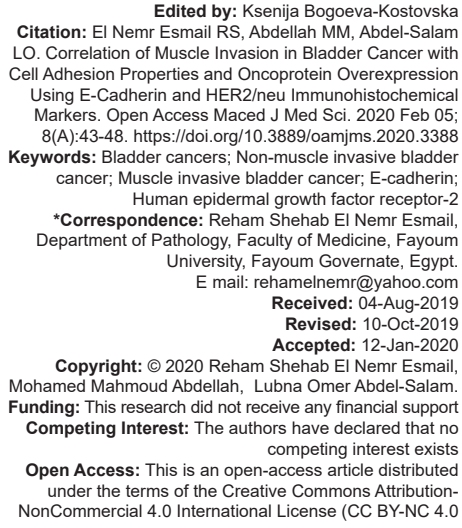

Citation: El Nemr Esmail RS, Abdellah MM, Abdel-Salam Cel Come Using E-Cadherin and HER2/neu Immunohistochemica (1/ldoi ords: Bladder cancers; Non-muscle invasive bladder th factor receptor-2 *Correspondence: Reham Shehab EI Nemr Esmail, ology, Faculty of Medicine, Fayoum Ersity, Fayoum Governate, Egypt Received: 04-Aug-2019 Accepted: $12-J a n-2020$ Conding: This research did not receive any financial support Competing Interest: The authors have declared that no NonCommercial 4.0 International License (CC BY-NC 4.0

\begin{abstract}
BACKGROUND: Most of bladder cancers are proven to be of urothelial origin (transitional cell carcinomas). Above $75 \%$ of them are of non-muscle invasive bladder cancer (NMIBC) type at presentation and the remainder are MIBC. Recent studies suggest that both are most probably two different categories based on both the histopathological and molecular features. The comprehensive understanding of the biomarkers expression in both categories will help in understanding the molecular event underlying each of them and may provide possible chances for targeted therapeutic options.

AIM: This study aims to study the differential expression of both E-cadherin and human epidermal growth factor receptor-2 (HER2) in the two categories of bladder cancer NMIBCs and MIBCs.

MATERIALS AND METHODS: A total of 40 blocks were collected retrospectively from cases of cancer bladder segregated as 20 cases NMIBCs and 20 cases MIBCs, subjected for E-cadherin and HER2 immunostaining.

RESULTS: E-cadherin showed positive expression in $65 \%$ of cases of NMI group and in $10 \%$ of the MI group, with high statistical significance ( $p<0.001)$. Regarding HER2, positive expression was seen in $25 \%$ of NMI cases and in $90 \%$ of $\mathrm{Ml}$ cases, with statistical significance $(\mathrm{p}<0.001)$. Comparison of the results of both markers and their correlation per case showed that $90 \%$ of tumors with muscle invasion were E-cadherin negative and HER2 positive. CONCLUSION: The significant association of loss of E-cadherin immunohistochemistry expression and positive HER2 overexpression in MIBC versus NMIBC figured out more differences between the two categories and added to the understanding of their biology. The possibility of validation of HER2-targeted therapy in MIBC cases is now strongly suggested.
\end{abstract}

\section{Introduction}

Bladder cancer is one of the most common cancers and the most common cancer of the urinary tract with above 350,000 new cases per year and more than 140,000 deaths per year worldwide [1]. In Western countries, it ranks the fifth among men cancers [2]. In Egypt, bladder cancer ranks second among the most commonly diagnosed malignancies in men [3]. Most of bladder cancers (above 90\%) are proven to be of urothelial origin (transitional cell carcinomas). Above $75 \%$ of them are of non-muscle invasive bladder cancer (NMIBC) type at presentation, and the remainder are MIBC [4].

Recent studies have evolved a model suggests that both NMBCs and MIBCs are most probably two different categories based on both the histopathological and molecular features [5]. Biologically; in most cases, the urothelial carcinoma cells do not have even the ability to invade. The clones that acquired this ability will definitely show different mutations and hence different molecular profile [6]. Moreover, another theory was introduced proposing that papillary NMIBC most likely develop through urothelial cell hyperplasia and gaining branching vascular channels, while MIBC is thought to develop through flat dysplasia - carcinoma in situ consequence. The biological and molecular features of each are, therefore, highly distinct [7]. The comprehensive understanding of the biomarkers expression in both categories will help in understanding the molecular event underlying each of them and may provide possible chances for targeted therapeutic options. E-cadherin is one of calcium-dependent transmembrane cadherin family member that is normally presents in epithelial cells and mediates cell adhesion [8]. It is now well understood that E-cadherin is a key stone in what is called epithelial mesenchymal transition (EMT), which is the basic step in tumor progression and both local and distant metastasis in different cancers [9].

However, the exact role of E-cadherin in cancer is still controversial and its role in cancer is still not well understood in each individual type of cancer. Although previous data suggested that E-cadherin acts as a tumor suppressor that is lost in advanced cancers, 
yet recent researches have confirmed that it has, as well, a cancer promoter function, as in cancer breast, where it shows overexpression in advanced cases [10]. The human epidermal growth factor receptor-2 (HER2/ neu) is a transmembrane glycoprotein and a wellknown member of the EGF family of tyrosine kinase receptors which is encoded by the HER2/neu protooncogene [11]. In normal cells, HER2 is involved in many biological processes including proliferation, differentiation, and angiogenesis [12]. In cancer cells, HER2 has been noticed to increase dramatically, and hence overexpressed in several malignancies [13], and some recent reports pointed to the possible involvement of HER2 in EMT in some cancers as breast cancer [14]. In bladder cancer, the role of HER2 is still controversial [11].

Some studies have highlighted that cadherindriven EMT function depends at least partially in their signaling pathways inside the tumor cells on ErbB family molecules [15]. Both E-cadherin and HER2 expression can modify the patient line of management and be a target for targeted therapy [16], [17].

The aim of this work was to study the differential expression of both E-cadherin and HER2 in the two categories of bladder cancer NMIBCs and MIBCs, aiming to better understanding of the biological differences between the two categories as well as to determine the possible role of targeted therapy in both groups.

\section{Materials and Methods}

\section{Cases}

A total of 40 blocks were collected retrospectively from cases of cancer bladder in Nasr Institute for treatment and research from cases in 2013 to 2018 as; 20 cases NMIBCs and 20 cases MIBCs.

Two unstained 3-5 $\mu \mathrm{m}$ thick sections were prepared from each block for further immunostaining.

\section{Immunohistochemistry}

Immunohistochemical staining was done using the EnVision (USA) method as follows:

Deparaffinization in xylene and rehydration in graded alcohol were done; then, the endogenous peroxidase activity was blocked by incubating the slides in $0.3 \%$ hydrogen peroxide for $10 \mathrm{~min}$. Dako target retrieval solution ( $\mathrm{pH} \mathrm{6.0)}$ was used for $20 \mathrm{~min}$; then, the slides were incubated for $60 \mathrm{~min}$ at room temperature with a rabbit polyclonal anti-HER2/ neu (Lab Vision Corp., Fremont, CA, USA, at 1:200 dilution), the Abcam mouse monoclonal Twist antibody
(1:100), and a mouse monoclonal antibody E-cadherin (Clone: NCH-38, Dako, USA). Slides are then washed with two changes of phosphate buffer saline, stained with secondary antibody (Dako, USA) for about $15 \mathrm{~min}$ at room temperature, then rinsed in the buffer. Slides were incubated for $1 \mathrm{~h}$ at room temperature. Positive control slides were also stained in the same run (normal urothelium was used as positive control for E-cadherin and intraductal carcinoma of breast tissues was used as positive control for HER2/neu).

E-cadherin was evaluated as follows [18]: Uniformly positive (+): More than $90 \%$ of tumor cells are stained (membranous), heterogeneous ( \pm ): More than 10 and $<90 \%$ of the tumor cells are positive (membranous and cytoplasmic), and negative: $<10 \%$ of the tumor cells were positive.

The positive uniform membranous staining pattern of the tumor cell is considered normal (positive) expression. Negative and heterogeneous staining pattern were considered to be negative (aberrant).

The original HercepTest ${ }^{\mathrm{TM}}$ was used for HER2 protein immunohistochemical detection. HER2 expression was classified according to the modified DAKO criteria as follows: Negative (scores 0/1+), equivocal (score $2+$ ), and positive (score $3+$ ), the cutoff for score $3+$ is more than $10 \%$ strongly positive cells. According to Kolla et al., 2008 [19], sections with scores 2 and 3 were considered as positive for HER2/ neu.

\section{Statistical analysis}

Data were coded and entered using statistical package SPSS version 21. Data were summarized using numbers and percentage for qualitative variables. Comparisons between the two studied groups were done using Chi-square test for the qualitative variables. Logistic regression analysis was done to test for significance predictors of muscle invasion in bladder cancer. $p \leq 0.05$ was considered as statistically significant.

\section{Results}

The study included 40 retrogressive cases. Cases are divided into two groups of 20 cases each:

Group 1: Urothelial carcinoma with negative muscle invasion included 8 females and 12 males, with the age ranged from 51 up to 65 with mean 56 years.

Group 2: Urothelial carcinoma with positive muscularis propria invasion included 4 females and 16 males, with the age ranged from 58 up to 72 with mean 66 years. 


\section{Immunohistochemical results}

E-cadherin (Figure 1 and Table 1) showed positive expression in $65 \%$ of cases of $\mathrm{NMI}$ group (13 case) and in 10\% of the Ml group (2 cases), with high statistical significance $(p<0.001)$.

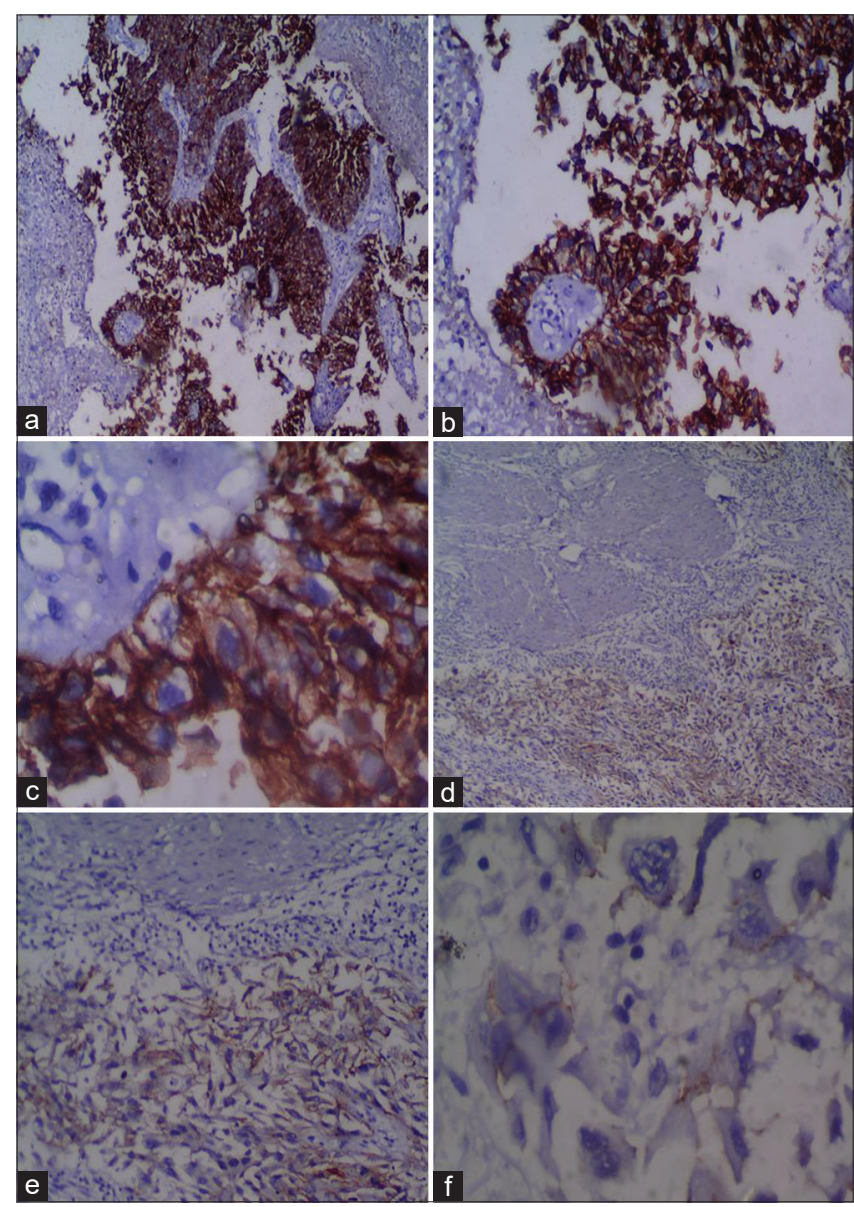

Figure 1: Results of E-cadherin: (a) $\times 10$, (b) $\times 40$, (c) $\times 200$. Section from a case of non-muscle invasive bladder cancer (MIBC) showing positive expression. (d) $\times 10$, (e) $\times 40$, (f) $\times 200$. Sections from highgrade MIBC showed aberrant (negative) immunostaining

According to the OR (0.06), E-cadherin expression is associated with lesser occurrence of muscle invasion.

Table 1: Results of immunohistochemical studies for E-cadherin and HER2 in the studied groups

\begin{tabular}{lllll}
\hline Marker & Status & MI $\mathrm{n}(\%)$ & $\begin{array}{l}\mathrm{NMI} \mathrm{n}(\%) \\
\mathrm{n}=20\end{array}$ & $\begin{array}{l}\text { Total } \mathrm{n}(\%) \\
\mathrm{n}=40\end{array}$ \\
\hline E-cadherin & Positive & $2(10)$ & $13(65)$ & $15(37.5)$ \\
E-cadherin & Negative & $18(90)$ & $7(35)$ & $25(62.5)$ \\
HER2 & Positive & $18(90)$ & $5(25)$ & $23(57.5)$ \\
HER2 & Negative & $2(10)$ & $15(75)$ & $17(42.5)$ \\
\hline
\end{tabular}

Regarding HER2 (Figure 2 and Table 1), positive expression was seen in $25 \%$ of $\mathrm{NMI}$ cases ( 5 cases) and in $90 \%$ of $\mathrm{Ml}$ cases (18 cases), with statistical significance $(p<0.001)$.

Positive Her2 is found to be associated with increase the risk of muscle invasion 27 folds than negative results $(O R=27.0)$.

Comparison of the results of both markers and their correlation per case showed that $90 \%$ of tumors with muscle invasion were E-cadherin negative and HER2 positive (Figure 3, Table 2).

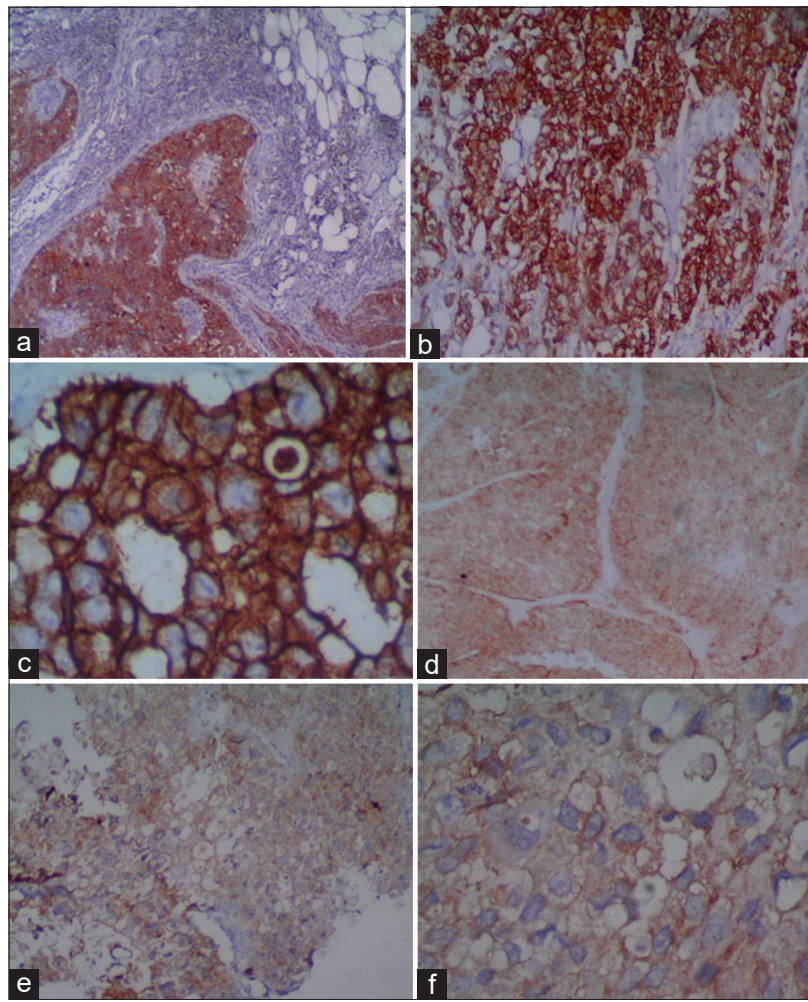

Figure 2: Results of HER2/neu immunostaining in the two studied groups. (a) $\times 10$, (b) $\times 40$, (c) $\times 200$. Sections from high-grade muscle invasive bladder cancer (MIBC) showed strong diffuse membranous HER2/neu immunostaining, considered positive. (d) $\times 10$, (e) $\times 40$, (f) $\times 200$. Sections from low-grade non-MIBC showed aberrant heterogeneous HER2/neu immunostaining, considered negative

On the other hand, $45 \%$ of tumors without muscle invasion were E-cadherin positive and HER2 negative.

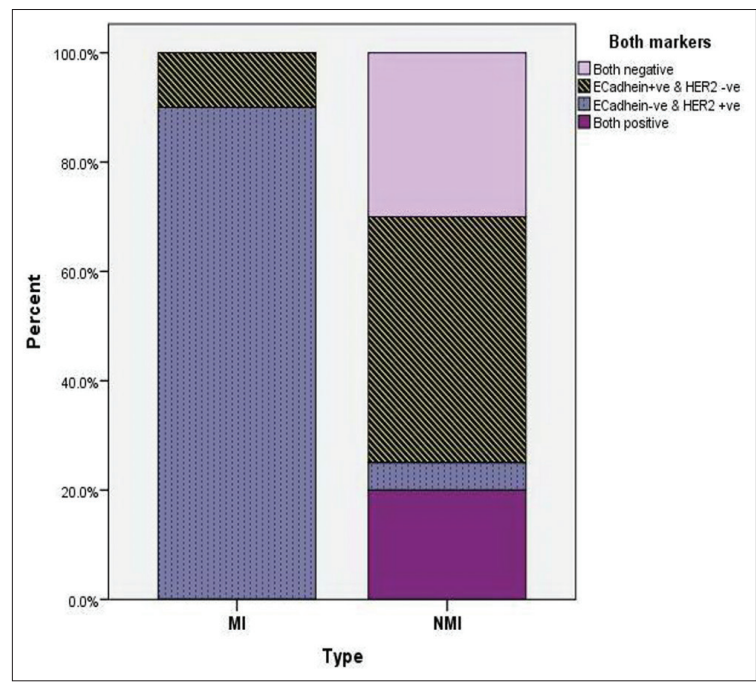

Figure 3: Combined results of E-cadherin and HER2 in the studied cases

The logistic regression test showed that the positivity of Her2 could predict muscle invasion. 
Table 2: Combined results of both E-cadherin and HER2 in the studied cases

\begin{tabular}{|c|c|c|c|}
\hline Studied group & MI n (\%) & NMI n (\%) & Total n (\%) \\
\hline Results & $n=20$ & $n=20$ & $\mathrm{n}=40$ \\
\hline Both negative & $0(0)$ & $6(30)$ & $6(15)$ \\
\hline E-cad -ve and HER2 +ve & $2(10)$ & $9(45)$ & $11(27.5)$ \\
\hline E-cad +ve and HER2 -ve & $18(90)$ & $1(5)$ & $19(47.5)$ \\
\hline Both positive & $0(0)$ & $4(20)$ & $4(10)$ \\
\hline Total & $20(100)$ & $20(100)$ & $40(100)$ \\
\hline
\end{tabular}

Moreover, similarly, the positivity of E-cadherin is considered a good prediction of non-muscle invasion.

\section{Discussion}

Bladder cancer was of great attention in Egypt due to its increasing rates and high treatment-associated morbidity [20]. Segregation of bladder urothelial cancer in two categories of NMIUB and MIUB is now becoming a trend that leads to study each category as a separate identity with increasing needs for deep understanding the biological and underlying biomarker expression in each group.

In this study, we examined E-cadherin and HER2 in both categories to assess their possible prognostic role and the applicability of targeted therapy in each.

In the present study, E-cadherin positivity was seen in $65 \%$ of non-muscle invasive group, opposing to $10 \%$ only in the muscle invasive group. Agreeing with our results, Jäger et al., 2010 [21], showed decreased positive E-cadherin staining in bladder cancer advanced stages and grades as well. Matching findings were also reached by Baumgart et al., 2007 [22], who demonstrated notable decrease in E-cadherin marker staining in their cases from NMIBC to MIBC in 572 UBC cases. D'Andrea et al. (2018) [23] examined E-cadherin as a proposed biomarker for recurrences prediction in NMIBC and although its positivity in most of the cases, E-cadherin failed to predict the recurrences in this study. Otto et al., 2017 [18], approved E-cadherin as a prognostic marker that is lost in progressive cases with above $75 \%$ positivity rate in their cases.

In their study, Kashibuchi et al., 2007 [24], compared the expression of $E$-cadherin and $\beta$-catenin in non-invasive and early invasive tumors versus invasive tumors. They showed a statistically significantly loss of both E-cadherin and $\beta$-catenin receptors in advanced stages and grades. Hu et al., 2011 [25], got similar findings; they studied 72 cases of UBC patients and confirmed increase aberrant staining (decreased positivity) of both $E$-cadherin and $\beta$-catenin with increase the tumor stage and its grade. Such mimicking results highlight the postulation of the inverse proportional relation of E-cadherin expression and muscle invasion.

In our study, $90 \%$ of the cases of MIUBCs showed positive overexpression for HER2/neu, with score +3 , in contrast to $25 \%$ of NMIUCs, with significant association of HER2 expression with muscle invasive cases. The expression in the positive cases was diffuse (70-100\% of tumor cells). These results agree with Hammam et al., 2015, study [26], which showed equivocal Her2 expression (score 2, which is considered negative in their study) in $23 \%$ of NMIBC cases and positive (score 3 ) expression in $43 \%$ and $46 \%$ of T1 and T2-3 tumors, respectively, with statistical significance.

Kolla et al., 2008 [19], showed positive expression in more than $70 \%$ of the MIBC cases and suggested that HER2 expression might provide an additional significant prognostic information for patients with bladder cancer. The diffuse strong expression of the HER2 in the positive cases was also described by Tschui et al., 2015 [27], in their study, they reported strong diffuse expression in $77 \%$ of the muscle invasive cases, they considered this a good indicator for the promising results of targeted therapy.

On the other hand, some studies denied the relation between HER2 expression and tumor progression. Latif et al., 2003 [28], showed rates of 76 and $52 \%$ in stages $\mathrm{Ta} / \mathrm{T} 1$ and $\mathrm{T} 2$ tumors, respectively, with insignificant difference $(p=0.06)$, and therefore, they concluded that increased HER2 protein overexpression may occur before tumor progression. Moreover, similarly, Agrawal et al., 2015 [29], noticed the overexpression of HER2 in NMIBCs and even more than in cases of MIBC.

From their study on bladder cancer cases, Mohammed et al., 2016 [7], concluded that HER2 overexpression is associated with muscle invasion and is predictor for poor survival and disease progression. As we did, they propose that HER2 is an independent risk factor for tumor progression. In the same regards, Ding et al., 2015 [30], suggested Her2 overexpression to be a risk factor for the detection of aggressive biological tendency in NMIBC.

HER2 expression in bladder cancer was very heterogeneous throughout different studies and this area is still poorly defined [31]. The notable variability in results between different studies as well as between the cases among each studied group in our results can be eventually explained in the context of genetic level and the newly named molecular classification of the bladder tumors into luminal and basal, as was suggested by Powles et al., 2016 [12].

We agree in this explanation together with the facts that the variability between studies in studying the gene expression using FISH technique versus the study of protein expression using immunohistochemistry technique added to the complexity of the comparing the results of different studies. Similarly, the interpretation of immunohistochemistry results (considering score 2 as negative or positive in results) markedly affected the results among different studies.

The association of HER2 overexpression in MIUCs over the NMIUCs relates well with the 
proposed fact that Her 2 overexpression is associated with bad prognosis and tumor progression Nagata et al., 2016 [32], through activating intracellular pathways enhancing tumor cells proliferation, motility, and invasion [13]. Cases of NMIBCs that display the overexpression may, therefore, carry bad prognostic indicator and may be considered a risk factor that requires even early cystectomy [33]. The controversial results of HER2 in bladder cancer was very obvious when Sanguedolce et al., 2018 [5], excluded HER2 from the prognostic factors of bladder cancer and denied its possible role as a targeted therapy, while in the same year, Sanguedolce et al., 2018, suggested HER2 as a predictor for the disease outcome [34].

From their study, Kiss et al., 2017 [13], stated that although MIBC showed the third highest rates in ERBB2 amplification and HER2 overexpression (after both breast and gastric cancers), yet the anti-HER2 treatments in MIBC have not shown encouraging results. They attributed this to the possible variation in the recently recognized bladder cancer molecular subtypes.

According to the results of the present study, the correlated results of both markers in the cases together with the logistic regression study pointed to the proposed idea that the advanced stages in bladder cancer may be correlated with loss of E-cadherin positivity and acquiring Her2 positivity.

Reviews had proved that EMT is usually associated with downregulation or total loss of E-cadherin protein expression (being an adhesion molecule and epithelial cell-cell junction marker). This step is also marked by upregulation of $\mathrm{N}$-cadherin protein (mesenchymal marker). The function of the later is noted to be depending on and related to HER2 at least partially. We propose that the notable inverse relation between E-cadherin expression and HER2 overexpression might be related to the role of each of them in EMT, which is a crucial step in all cancers' progression [15].

\section{Conclusion}

The significant association of loss of E-cadherin immunohistochemistry expression and positive Her2 overexpression in MIBC versus NMIBC figured out more differences between the two categories and added to the understanding of their biology. Both Her2 overexpression and E-cadherin negativity are proposed as risk factors for occurrence of muscle invasion in small superficial biopsies. The possibility of validation of Her2-targeted therapy in MIBC cases is now strongly suggested.

\section{References}

1. Marcelino $Y$, Peter W, Sunjay J. Bladder cancer. Medicine. 2016;44(1):52-5.

2. Ploeg M, Aben KK, Kiemeney LA. The present and future burden of urinary bladder cancer in the world. World $\mathrm{J}$ Urol. 2009;27(3):289-93. https://doi.org/10.1007/s00345-009-0383-3 PMid: 19219610

3. Zheng YL, Amr S, Saleh D, Dash C, Ezzat S, Mikhail NN, et al Urinary bladder cancer risk factors in Egypt response. Cancer Epidemiol Biomarkers Prev. 2012;21(3):537-46. https://doi. org/10.1158/1055-9965.epi-11-0589

4. Kaufman DS, Shipley WU, Feldman AS. Bladder cancer. Lancet. 2009;374(9685):239-49. https://doi.org/10.1016/ s0140-6736(09)60491-8

5. Sanguedolce F, Cormio A, CalT B, Buffi N, Autorino R, Cormi L. Molecular markers predicting disease outcome in bladder cancer. Should we shift from the classical cell-cycle regulators to HER2 oncogene? GGJ. 2018;66:239-44.

6. Sjudahl G, Jackson CL, Bartlett JM, Siemens DR, Berman DM. Molecular profiling in muscle-invasive bladder cancer: More than the sum of its parts. J Pathol. 2019;247:563-73. https://doi. org/10.1002/path.5230

PMid:30604486

7. Mohammed AA, El-Tanni H, El-Khatib HM, Mirza AA, Mirza AA, Alturaifi TH. Urinary bladder cancer: Biomarkers and target therapy, new era for more attention. Oncol Rev. 2016;10(2):320. https://doi.org/10.4081/oncol.2016.320

8. Singh A, Settleman J. EMT, cancer stem cells and drug resistance: An emerging axis of evil in the war on cancer. Oncogene. 2010;29(34):4741-51. https://doi.org/10.1038/ onc.2010.215

PMid:20531305

9. Bryan RT, Atherfold PA, Yeo Y, Jones LJ, Harrison RF, Wallace DM, et al. Cadherin switching dictates the biology of transitional cell carcinoma of the bladder: Ex vivo and in vitro studies. J Pathol. 2008;215(2):184-94. https://doi.org/10.1002/ path.2346

PMid: 18393367

10. Petrova $\mathrm{YI}$, Schecterson L, Gumbiner BM. Roles for E cadherin cell surface regulation in cancer. Mol Biol Cell. 2016;27(21):3181 375. https://doi.org/10.1091/mbc.e16-01-0058

11. Zhao J, Xu W, Zhang Z, Song R, Zeng S, Xu C. Prognostic role of HER2 expression in bladder cancer: a systematic review and meta analysis. Int Urol Nephrol. 2015;47(1):87-94. https://doi. org/10.1007/s11255-014-0866-z

PMid:25384433

12. Powles, T., Huddart R. Elliot T. Phase III, double-blind, randomized trial that compared maintenance lapatinib versus placebo after first-line chemotherapy in patients with human epidermal growth factor receptor $1 / 2$ positive metastaic bladder cancer. J Clin Oncol. 2016;66:3468. https://doi.org/10.1016/j. eururo.2017.05.027

13. Kiss B, Wyatt AW, Douglas J, Skuginna V, Mo F, Anderson S, et al. HER2 alterations in muscle-invasive bladder cancer: Patient selection beyond protein expression for targeted therapy. Sci Rep. 2017;16(7):42713. https://doi.org/10.1038/ srep42713

14. Ai M, Liang K, Lu Y, Qiu S, Fan Z. Brk/PTK6 cooperates with HER2 and Src in regulating breast cancer cell survival and epithelial-to-mesenchymal transition. Cancer Biol Ther. 2013;14(3):237-45. https://doi.org/10.4161/cbt.23295 PMid:23291984

15. Wang M, Ren D, Guo W, Huang S, Wang Z, Li Q, et al. 
$\mathrm{N}$-cadherin promotes epithelial-mesenchymal transition and cancer stem cell-like traits via ErbB signaling in prostate cancer cells. Int J Oncol. 2015;48(2):595-606. https://doi.org/10.3892/ ijo.2015.3270

PMid:26647992

16. Carneiro BA, Meeks JJ, Kuzel TM, Scaranti M, Abdulkadir SA, Giles FJ. Emerging therapeutic targets in bladder cancer. Cancer Treatment Rev. 2015;41(2):170-8. https://doi.org/10.1016/j. ctrv.2014.11.003

PMid:25498841

17. Morera DS, Hennig MS, Talukder A, Lokeshwar SD, Wang J, Garcia-Roig M, et al. Hyaluronic acid family in bladder cancer: Potential prognostic biomarkers and therapeutic targets. $\mathrm{Br}$ J Cancer. 2017;117(10):1507-17. https://doi.org/10.1038/ bjc. 2017.318 PMid:28972965

18. Otto W, Breyer J, Herdegen S, Eder F, Bertz S, May M, et al. WHO 1973 grade 3 and infiltrative growth pattern proved, aberrant E-cadherin expression tends to be of predictive value for progression in a series of stage T1 high-grade bladder cancer after organ-sparing approach. Int Urol Nephrol. 2017;49(3):4317. https://doi.org/10.1007/s11255-016-1491-9 PMid:28035618

19. Kolla SB, Seth A, Singh MK, Gupta NP, Hemal AK, Dogra PN, et al. Prognostic significance of HER2/neu overexpression in patients with muscle invasive urinary bladder cancer treated with radical cystectomy. Int Urol Nephrol. 2008;40(2):321-7. https://doi.org/10.1007/s11255-007-9283-x

\section{PMid:17899426}

20. Kyritsi F, Loffredo CA, Zheng YL, Philips G, Amr S. Urinary bladder cancer in Egypt: Are there gender differences in its histopathological presentation? Adv Urol. 2018;13:3453808. https://doi.org/10.1155/2018/3453808

21. Jgger T, Becker M, Eisenhardt A, Tilki D, Tutsch M, Schmid KW, et al. The prognostic value of cadherin switch in bladder cancer. Oncol Rep. 2010;23(4):1125-32.

PMid:20204300

22. Baumgart E, Cohen MS, Neto BS, Jacobs MA, Wotkowicz C, Rieger-Christ KM, et al. Identification and prognostic significance of an epithelial-mesenchymal transition expression profile in human bladder tumors. Clin Cancer Res. 2007;13(6):1685-94. https://doi.org/10.1158/1078-0432.ccr-06-2330

PMid: 17363521

23. D'Andrea D, Hassler MR, Abufaraj M, Soria F, Ertl IE, Ilijazi D, et al. Progressive tissue biomarker profiling in nonmuscle-invasive bladder cancer. Expert Rev Anticancer Ther. 2018;18(7):695-703. https://doi.org/10.1080/14737140.2018.14 74104

\section{PMid:29737231}

24. Kashibuchi K, Tomita K, Schalken JA, Kume H, Takeuchi T, Kitamura T. The prognostic value of E-cadherin, alpha-, beta- and gamma-catenin in bladder cancer patients who underwent radical cystectomy. Int J Urol. 2007;14(9):789-94. https://doi.org/10.1111/j.1442-2042.2007.01830.x

PMid: 17760743

25. Hu X, Ruan Y, Cheng F, Yu W, Zhang X, Larré S. p130Cas,
E-cadherin and $\beta$-catenin in human transitional cell carcinoma of the bladder: Expression and clinicopathological significance. Int J Urol. 2011;18(9):630-7. https://doi. org/10.1111/j.1442-2042.2011.02793.x

PMid:21672035

26. Hammam $\mathrm{O}$, Nour $\mathrm{HH}$, Mosaad $\mathrm{M}$, Akl M, Khalil $\mathrm{H}, \mathrm{A}$ Ganzory $\mathrm{H}$, et al. The clinical significance of HER2 protein amplification/expression in urinary bladder lesion. Arab J Urol. 2015;13(2):146-52. https://doi.org/10.1016/j.aju.2015.01.004 PMid:26413337

27. Tschui J, Vassella E, Bandi N, Baumgartner U, Genitsch V, Rotzer D, et al. Morphological and molecular characteristics of HER2 amplified urothelial bladder cancer. Virchows Archiv Heidelberg. 2015;466(6):703-10. https://doi.org/10.1007/ s00428-015-1729-4 PMid:25809292

28. Latif Z, Watters AD, Dunn I, Grigor KM, Underwood MA, Bartlett JM. HER2/neu overexpression in the development of muscle- invasive transitional cell carcinoma of the bladder. Br J Cancer. 2003; 89(7):1305-9. https://doi.org/10.1038/ sj.bjc. 6601245

PMid: 14520464

29. Agrawal V, Mandhani A, Pandey R, Agarwal V. HER2/neu $2+$ protein expression by immunohistochemistry in urothelial bladder cancer is not associated with gene amplification by in situ hybridization. Am J Clin Pathol. 2015;144(2):A376. https:// doi.org/10.1093/ajcp/144.suppl2.376

30. Ding W, Tong S, Gou Y, Sun C, Wang H, Chen Z, et al. Human epidermal growth factor receptor 2: A significant indicator for predicting progression in non-muscle-invasive bladder cancer especially in high- risk groups. World J Urol. 2015;33(12):19517. https://doi.org/10.1007/s00345-015-1557-9

31. Vidal RM, Mota SR, Hayden A, Markham H, Douglas J, Packham G, et al. Epidermal growth factor receptor family inhibition identifies p38 mitogen-activated protein kinase as a potential therapeutic target in bladder cancer. Urology. 2018;112(225):e1-225.e7. https://doi.org/10.1016/j. urology.2017.10.041

PMid:29154981

32. Nagata M, Muto S, Horie S. Molecular biomarkers in bladder cancer: Novel potential indicators of prognosis and treatment outcomes. Dis Markers. 2016;2016:8205836. https://doi. org/10.1155/2016/8205836 PMid:26924873

33. Breyer J, Otto W, Wirtz RM, Wullich B, Keck B, Erben P, et al. ERBB2 expression as potential risk-stratification for early cystectomy in patients with $\mathrm{pT} 1$ bladder cancer and concomitant carcinoma in situ. Urol Int. 2017;98(3):282-9. https://doi. org/10.1159/000453670

PMid:27992871

34. Sanguedolce F, Russo D, Mancini V, Selvaggio O, Calт B, Pagliarulo V, et al. Human epidermal growth factor receptor 2 in non-muscle invasive bladder cancer: Issues in assessment methods and its role as prognostic/predictive marker and putative therapeutic target: A comprehensive review. Urol Int. 2018;21:1-13. https://doi.org/10.1159/000494359 